\title{
Patterns of Stress Experienced by Secondary School Teachers in Choma District of Southern Province of Zambia
}

\author{
Kennedy Kanene \\ University of Botswana \\ Botswana \\ Demian Mwendabai Mushungekelwa \\ Batoka Secondary School \\ Zambia
}

Received: Feb. 3, 2016 Accepted: April 10, 2016 Published: May 1, 2016

doi:10.5296/jse.v6i2.9910 URL: http://dx.doi.org/10.5296/jse.v6i2.9910

\begin{abstract}
The present paper presents the results of the study that investigated the patterns of stress experienced by secondary school teachers in Choma District of Zambia. The study objectives included; to establish the forms of stress faced by teachers; and to recommend solutions to the identified patterns of stress. A descriptive survey design was used in the study where a sample of six secondary schools and 120 teacher were selected from the District using the simple random sampling technique. The Teacher Stress Inventory (TSI) questionnaire was employed in the study. According to the study teachers moderately experienced patterns of stress in terms of, emotional manifestation, fatigue manifestation, cardiovascular manifestation, and gastronomic manifestation but rarely experienced stress in terms of behavioural manifestation. This could be minimised by the Ministry of Education conducting seminars and workshops for the teachers on stress prevention and management together with School head teachers organising leisure events for teachers to allow teachers to refresh and be rejuvenate.
\end{abstract}

Keywords: Patterns of Stress, Choma, stress manifestation, Teacher Stress Inventory, leisure events 


\section{Introduction}

A study on levels of occupational stress among teachers in Lusaka urban basic schools in Zambia conducted by Makasa (2013) reveals that $95 \%$ of respondents felt irritated by the nature of their working environment (Makasa: 2003). Results further reveal that $38 \%$ of respondents encountered conflicts with peers often. A further $59 \%$ of the respondents acknowledges experiencing healthy related problems due to pressure of work. Accordingly, $81 \%$ of the respondents rated stress levels as often. From this study it can be concluded that stress is prevalent among teachers at basic school levels.

Teacher stress is defined as the experience by a teacher of negative, unpleasant emotions such as lesson, anger, and depression as a result of one aspect of their work (Sprenger, 2011). According to Mlaki (2012), school principals should be particularly concerned about the effect of teacher stress on the academic outcomes for their students. This is fundamentally so because the effects of stress on individual teachers affect the classroom environment and learning, in due course compromising the academic performance of the learners at various levels of assessment (Kanene \& Mushungekelwa, 2016). It is therefore critical that an investigation on the manifestation or patterns of stress among secondary school teachers in Zambia is conducted so as to avail school managers, Ministry of Education with data in this regard. The information may apprise these secondary school administrators on the need to tackle stress among teachers.

\subsection{Problem Statement}

A number of scholars including Pryor and Maples (2011) and Makasa (2013) have identified stress as one the maladies suffered by secondary school teachers in Zambia. They posit that stress is caused by a diversity of factors and that it may result in dire consequences among teachers. It is the aim of this study to establish the forms through which stress manifests itself among the secondary school teachers in Choma District southern of Zambia.

\subsection{Purpose of the Study}

To investigate the patterns of stress experienced by secondary school teachers in Choma District of Zambia.

\subsection{Objectives of the Study}

1. To establish the forms of stress faced by teachers; and

2. To recommend solutions to the identified patterns of stress.

\section{Literature Review}

According to Schultz and Schultz (2010), stress among teachers is related to absent turnover and early retirement which negatively affects the climate of the school and lead to poor student outcomes, both academically and behaviourally. When teachers are stressed they are often irritable, impatient and easily frustrated by their students, and they are unable to provide the necessary support to help students succeed in the classroom and beyond. 
The existence of stress depends on the existence of the stressor. Accordingly, Wilson (2010) says stress is a mental or physical phenomenon formed through one's cognitive appraisal of the stimulation. It is a result of one's interaction with the environment. Wilson (ibid) defines stress as anything that challenges an individual's adaptability or stimulates an individual's body or mentality. Stress can be caused by environment factors, psychological factors, biological factors and social factors. It can be negative or positive to an individual, depending on the strength and persistence of the stress, the individual's personality, cognitive appraisal of the stress and social support.

Studies conducted on job satisfaction and occupational stress among teachers in Ireland revealed that three out of every 10 teachers related their job as very or extremely stressful. In his study gender of a teacher, age-group taught, and teaching experience were found to be mediators of teacher stress (Mlaki, 2012).

Demographics characteristics of teachers revealed that stress affect them in different ways. Chan (2010) identified biographical factors with regard to job stress in the United Kingdom among Primary Schools teachers and found significant differences between men and women, and teachers of different ages and length of teaching experience. Male teachers reported more stress than their female counterparts in relation to professional tasks and pupil behaviour/ attitude. Female teachers scored higher than males on professional concerns. Just over one third of all teachers were satisfied with their job. When specific facts of job satisfaction were examined, teachers were most satisfied with their professional performance and least satisfied with teaching resources. Teacher stress and job satisfaction were found to be negatively correlated with high reports of occupational stress related to low levels of job satisfaction (Nabirye, Brown, Pryor \& Maples, 2011).

With regard to gender differences in stress experiences, female teachers were less stressed compared to male teachers. In Canada, a survey of over 2, 000 elementary school teachers found that female teachers were more satisfied with their professional role as a teacher compared to their male counterparts. The gender gap in professional satisfaction grew with increased teaching experience (Romer, 2011).

A study on genders differences with regard to stress in Ireland among teachers by Richards (2012) found that teachers experienced moderate to high levels of stress compared to other occupational groups. In terms of generic occupational stress, the five highest scoring items among members were: workload, insufficient resources with which to work, being undervalued, and equipment and not bring able to switch off at home. Teaching-specific stress was associated with lack of time to spend with individual pupils, large classes, noisy pupils, and difficulty class and pupil motivation. The top ten sources of self-reported stress included: the pupil- teacher relation, discipline , pupil motivation, inadequate resources, lack of parental support, teaching groups of differing ability, workload, parental expectations, salary, supervision for covering for absent teachers and demands on after school time (Bagdonas, 2010).

Darmirtas (2010) indicates that the levels of stress experienced as well as outcomes of stress such as burnout and psychological distress may be dependent on coping strategies that an 
individual employ and on the situation. If a coping method is effective a teaching stressor should be reduced or eliminated, thus decreasing potential negative outcomes. On the other hand, an ineffective coping method may result in maintaining or increasing teacher stress, thus potentially increasing the negative outcomes such as a burnout and psychological distress (Darmirtas, 2010). Specifically job satisfaction may predict the teacher's level of stress.

Eckert and William cited in Makasa (2013) found that stress was associated with some health problems that affect many teachers in many countries. Essentially, a study among teachers in the USA reveals stress as the commonest health problem (Landsman, 1978 cited in Makasa, 2013). In this case teaching is identified not only as hard work; it can be full of stress. Pressure due to school reform efforts, inadequate administrative support poor working conditions, lack of administrative support, poor working conditions, lack of participation in school decision making, the burden of paper work, and lack of resources have been identified as factors that can cause stress among school staff (Makasa, ibid).

In fact Cheng, Yuan-Wen and Chung-Yuan (2010) argue that the change in the teaching profession in the last few years to become more focused on 'clients', the students and their parents, makes the teaching environment with more disrespectful students and parents who are likely to question their decisions. Teachers also must occasionally deal with difficulty co-workers, unfriendly work environments and stringent deadlines. As technology changes, teachers must also learn how to integrate new technologies into their classrooms. Romano and Wahlstorm in Harlow (2010) outlines five major sources of stress student demands, physical demands of teaching, lack of funding, after school and evening meeting, and demands of inefficient school administration.

Furthermore, Hallow (2010) reveals that Australian teachers experience stress as a result of threats of physical abuse, verbal abuse, work refusal by student, dealing with consequences of abuse or neglect of students and dealing with aggressive and abusive parents. Justin, Shan and Mauncer in Harlow (2010) found that the main sources of stress for teachers in the United Kingdom were work related stressors, such as time management, student discipline and student motivation. Other sources of teacher stress that have been documented include teaching a child with a disability, discipline and handling difficulty students, adapting to change, lack of time, inadequate resources, poor student behaviour, multiple roles and responsibilities and role conflict (Cheng, Yuan-Wen \& Chung-Yuan, 2010).

Chaplain (1995) cited in Hallow (2010) found that there was a tendency for less experienced teachers to be more stressed by professional concerns than experienced teachers. Overall, the two- groups that were most likely to experience the highest stress levels were the youngest teachers and the oldest teachers. Also that female teachers experienced more stress than male teachers.

Much research has been done on manifestations of stress among teachers over the last 20 years. Due to the large volume of research in this area, this study focussed on the patterns of stress experienced by secondary school teachers in Choma District of Zambia. 
Richards (2012) states that patterns of stress refer to manner in which stress manifests itself among employees in an organisation. Stress is considered as an involuntary response to a dangerous situation. Stress is considered as an involuntary response to a dangerous situation. When presented with pressure that the brain is incapable of handling, it puts the body on alert by producing hormones which are required in fight or fright situation (ibid). The following section discusses manifestations of stress in the context of this study.

\subsection{Emotional Manifestations}

According to Klassen (2010), emotional manifestations of stress include becoming easily agitated, frustrated, and becoming moody. Other emotional manifestation may include feeling overwhelmed, having difficulty relaxing, feeling bad about one self (low self-esteem), lonely, worthless and depressed. In a study by Riaz and Ramzan (2013) on recognition of stressors and manifestation of stress among university teachers it was revealed that most lectures acknowledged being overwhelmed and felt frustrated with the demand of the work.

\subsection{Fatigue Manifestation}

Fatigue is a feeling of constant tiredness or weakness and can be physical, mental or a combination of both. In this regard, each year, around 1.5 million Australians see their doctors about fatigue (Soylu, 2013). According to Klassen (2010), fatigue is a symptom, not a condition. In fact, fatigue is caused by a combination of lifestyle, social, psychological and general wellbeing issues rather than an underlying medical condition. Fatigue can cause a vast range of other physical, mental and emotional symptoms including: chronic tiredness or sleepiness, headache, dizziness, sore or aching muscles, muscle weakness, slowed reflexes and responses, impaired decision-making and judgement, moodiness, such as irritability, impaired hand-to-eye coordination, appetite loss, reduced immune system function, blurry vision, short-term memory problems, poor concentration, hallucinations, reduced ability to pay attention to the situation at hand and low motivation to mention but a few (Klassen, 2010; Richards, 2012; Soylu, 2013).

Richards (2012) declares that the wide range of causes that can trigger fatigue include: Medical causes; unrelenting exhaustion which may be a sign of an underlying illness such as a thyroid disorder, heart disease or diabetes. Lifestyle-related causes; alcohol or drugs or lack of regular exercise can lead to feelings of fatigue. Workplace-related causes; workplace stress which can lead to feelings of fatigue emotional concerns and stress. According to Sprenger (2011), fatigue is a common symptom of mental health problems, such as depression and grief, and may be accompanied by other signs and symptoms, including irritability and lack of motivation.

\subsection{Cardiovascular Manifestation}

Cardiovascular manifestations of stress include; heart disease, high blood pressure, abnormal heart rhythms, heart attacks and stroke. A study conducted by Demirtas (2010) in the United States of America on manifestations of stress among teachers in primary schools indicates that behavioural and cardiovascular manifestations were prevalent among teachers. In this 
regard, teachers are affected by increased blood pressure, heart racing and the use of alcohol as a way combat stress.

\subsection{Gastronomic Manifestation}

Gastronomic manifestations of stress include, stomach pains, stomach cramps and loss of appetite to mention but a few. Richards (2012) states that when presented with pressure that the brain is incapable of handling, it puts the body on alert by producing hormones which are required in fight or fright situation. This may result in increased blood pressure, rapid heartbeat, reduced blood supply to the skin, cessation of digestive activities, increased respiration, additional release of sugar and decrease in immune system functions to preserve it for later action.

Abbasi (2011) says that patterns of stress at work evokes different reactions in different individual teachers. One of the reasons for this is that some categories of people are better able to cope with stress than others. They have resources at their disposal which enable them to adapt their behaviour in ways that meet environmental challenges. All these actions have a very long lasting negative effect which may lead to serious and even fatal conditions such as; depression and anxiety, alcoholism, drug dependency, congenital heart diseases and stress related diabetes (Richards, 2012; Abbasi, 2011).

\subsection{Behavioural Manifestation}

Accordingly, Purna (2011) posits that behavioural manifestations of stress include; changes in appetite, procrastinating and avoiding responsibilities, increased use of alcohol, drugs or cigarettes by the workers who is affected by a stressful situation. The use of alcohol may be employed as a way of supressing the feelings and thoughts which cause discomfort. This may be also in form of absenteeism from work without any concrete reasons, which may have grave consequences for both the teacher and the learners in terms work coverage. A study conducted by Shahin (2011) on the relationship between self-efficacy and stress among Iranian teachers revealed that teachers acknowledged having changes in appetite and avoiding certain responsibilities because of stressful situations in their work place.

\section{Methodology of the Study}

The descriptive or survey research design was adopted for the study. The population consisted of 440 secondary school teachers from 11 government secondary schools in Choma District of Zambia. The simple random sampling techniques was used to select six secondary schools in the District, and 20 teachers were selected from each school using the simple random sampling technique. A total of 120 respondents were selected for the study.

The Teacher Stress Inventory questionnaire (TSI) adapted from Fimian (1988), comprising 49 items of the five point Likert scale, was used to collect data. A pilot study was conducted on two secondary schools which were not included in the main study to ascertain the reliability of the instrument. The instrument was administered to 30 respondents by the researchers. 


\section{Ml Macrothink}

The data collected was coded and analysed using the Statistical Packages for Social Sciences (SPSS) version 22. Descriptive statistics in form of frequencies, percentages, mean and standard deviation were used in the research.

Table 1 and 2 below were used for the interpretation of mean scores. Table 1 was used for the interpretation of the various items while table 2 was used for the overall means which indicated the extent to which teachers experienced the various sources and patterns of stress.

Table 1. Interpretation of Mean Scores

\begin{tabular}{|l|l|l|l|}
\hline Scale & Response & Mean score & Verbal Interpretation \\
\hline 5 & Strongly agree & $4.51-5.00$ & Strongly agree \\
\hline 4 & Agree & $3.51-4.50$ & Agree \\
\hline 3 & Undecided & $2.51-3.50$ & Undecided \\
\hline 2 & Disagree & $1.51-2.50$ & Disagree \\
\hline 1 & Strongly disagree & $1.00-1.50$ & Strongly disagree \\
\hline
\end{tabular}

Table 2. Interpretation of Mean Scores

\begin{tabular}{|l|l|l|l|}
\hline Scale & Response & Mean score & Verbal Interpretation \\
\hline 5 & Strongly agree & $4.51-5.00$ & Very Highly Experienced \\
\hline 4 & Agree & $3.51-4.50$ & Highly Experienced \\
\hline 3 & Undecided & $2.51-3.50$ & Moderate Experienced \\
\hline 2 & Disagree & $1.51-2.50$ & Rarely Experienced \\
\hline 1 & Strongly agree & $1.00-1.50$ & Never Experienced \\
\hline
\end{tabular}

\section{Data Presentation and Discussion}

The data was analysed using the descriptive statistics. The results were presented in relation to the research questions as indicate below.

To what degree do teachers experience patterns of stress in terms of, emotional manifestation, fatigue manifestation, cardiovascular manifestation, gastronomic Manifestation, behaviour manifestations? 


\section{Ml Macrothink}

Table 3 shows the degree to which teachers experienced patterns of stress in terms of emotional manifestation.

Table 3. Emotional Manifestations

\begin{tabular}{|l|l|l|}
\hline Item & Mean & Std. Deviation \\
\hline I respond to stress by feeling insecure & 3.11 & 1.338 \\
\hline I respond to stress by feeling vulnerable & 2.98 & 1.218 \\
\hline I respond to stress by feeling unable to cope & 2.93 & 1.178 \\
\hline I respond to stress by feeling depressed & 3.09 & 1.217 \\
\hline I respond to stress by feeling anxious & 3.22 & 1.162 \\
\hline Average & 3.0680 & .74882 \\
\hline
\end{tabular}

From the table 3, teachers were undecided on whether they responded to stress by feeling insecure, vulnerable, unable to cope, depressed and anxious with the means ranging from 2.93-3.22. The high standard deviations between 1.161-1.338 indicated that teachers were heterogeneous in their responses. The overall mean of 3.0680 showed that teachers moderately experienced patterns of stress in terms of emotional manifestation and were homogeneous in their responses with a standard deviation of 0.74882 .

Table 4 below shows the degree to which teachers experienced patterns of stress in terms of fatigue manifestation.

Table 4. Fatigue Manifestations

\begin{tabular}{|l|l|l|}
\hline Item & Mean & Std. Deviation \\
\hline I respond to stress by sleeping more than usual & 2.93 & 1.212 \\
\hline I respond to stress by procrastinating & 2.80 & 1.268 \\
\hline I respond to stress by becoming fatigued in a very short time & 3.03 & 1.179 \\
\hline I respond to stress with physical exhaustion & 3.27 & 1.223 \\
\hline I respond to stress with physical weakness & 2.99 & 1.214 \\
\hline Average & 3.0020 & .65896 \\
\hline
\end{tabular}




\section{NI Macrothink}

From the table teachers were undecided on whether they responded to stress by sleeping more than usual, procrastinating, becoming fatigued in a short time, with physical exhaustion and with physical weakness with means ranging from 2.80-3.27. The high standard deviations between 1.179-1.268 for all the items indicate that teachers were heterogeneous in their responses. The overall mean of 3.0020 shows that teachers moderately experienced patterns of stress in terms of fatigue manifestations and were homogeneous in their responses with a standard deviation of 0.65896 . This finding is in agreement with a study by Riaz \& Ramzan (2013) who found that University teachers moderately experienced pattern of stress in terms of fatigue manifestation with the mean of 2.6118 .

Table 5 shows the degree to which teachers experienced patterns of stress in terms of cardiovascular manifestations.

Table 5. Cardiovascular Manifestations

\begin{tabular}{|l|l|l|}
\hline Item & Mean & Std. Deviation \\
\hline I respond to stress with feelings of headache & 3.32 & 1.181 \\
\hline I respond to stress with feelings of heart pounding or racing & 3.16 & 1.216 \\
\hline I respond to stress with rapid and/or shallow breath & 2.81 & 1.202 \\
\hline Average & 3.0962 & .80069 \\
\hline
\end{tabular}

According to table 5, teachers were undecided on whether they responded to stress with feeling of headache, heart pounding or racing, and with rapid and/or shallow breath with means ranging from 2.81-3.32. The high standard deviations between 1.181-1.216 indicates that teachers were heterogeneous in their responses.

The overall mean of 3.0962 shows that teachers moderately experienced patterns of stress in terms of cardiovascular manifestation and were homogeneous in their responses with a standard deviation of 0.80069 . This finding concurs with a study by Riaz \& Ramzan (2013) who found that University teachers moderately experienced pattern of stress in terms of cardiovascular manifestation with the mean of 3.0821 .

Table 6 shows the degree to which teachers experience patterns of stress in terms of gastronomic manifestation. 
Table 6. Gastronomic Manifestations

\begin{tabular}{|l|l|l|}
\hline Item & Mean & $\begin{array}{l}\text { Std. } \\
\text { Deviation }\end{array}$ \\
\hline I respond to stress with stomach pain of extended duration & 2.68 & 1.198 \\
\hline $\begin{array}{l}\text { I respond to stress with stomach cramps(stomach ache of short } \\
\text { duration) }\end{array}$ & 2.62 & 1.231 \\
\hline I respond to stress with loss of appetite & 2.91 & 1.211 \\
\hline Average & 2.7381 & .92842 \\
\hline
\end{tabular}

The table indicates that teachers were undecided on whether they responded to stress with stomach pain of extended duration, stomach cramps (stomach ache of short duration) and loss of appetite with the means of 2.68, 2.62 and 2.91 respectively. The high standard deviations of $1.198,1.231$ and 1.211 for all the three items respectively indicates that the teachers were heterogeneous in their responses.

The overall mean of 2.7381 showed that teachers moderately experienced patterns of stress in terms of gastronomic manifestations and were homogeneous in their responses with a standard deviation of .92842 . This finding is in agreement with a study by Riaz \& Ramzan (2013) who found that University teachers moderately experienced pattern of stress in terms of gastronomic manifestation with the mean of 3.005.

Table 7 below shows the degree to which teachers experienced patterns of stress in terms of behavioural manifestations.

Table 7. Behavioural Manifestations

\begin{tabular}{|l|l|l|}
\hline Item & Mean & Std. Deviation \\
\hline I respond to stress by using over the counter drugs & 2.47 & 1.302 \\
\hline I respond to stress by using prescription drugs & 2.26 & 1.277 \\
\hline I respond to stress by using alcohol & 2.15 & 1.334 \\
\hline I respond to stress by calling my supervisor that am sick & 2.42 & 1.346 \\
\hline Average & 2.3273 & 1.01638 \\
\hline
\end{tabular}


It is evident from table 7 that teachers disagreed on all the four items with means ranging from 2.15-2.47 that they responded to stress by using over the counter drugs, prescription drugs, alcohol or calling in sick. The high standard deviations between 1.277-1.346 indicated that teachers were heterogeneous in their responses.

The overall mean of 2.3273 showed that teachers rarely experienced patterns of stress in terms of behavioural manifestations and showed heterogeneity in their responses with a standard deviation of 1.01638. This finding is in disagreement with a study by Riaz and Ramzan (2013) in Pakistan who found that University teachers moderately experienced pattern of stress in terms of behavioural manifestation with the mean of 3.124. in fact, in both studies responses were heterogeneous.

\section{Conclusion and Recommendations}

It was evident from this study that teachers in Choma District, Zambia experienced stress and manifestation of stress. The study revealed that teachers moderately experienced patterns of stress in terms of emotional manifestation, fatigue manifestation, cardiovascular manifestation and gastronomic manifestation but rarely experienced patterns of stress in terms of behavioural manifestation. In order to minimise the levels of stress experienced by secondary school teachers we suggest that the Ministry of Education should consider conducting seminars and workshops for the teachers on stress prevention and management. Also, School head teachers should consider organising leisure events for teachers such as end of term or year outings which will allow teachers to refresh and revitalise their energy (Kanene \& Mushungekelwa, 2016).

\section{References}

Abel, H. M., \& Sewell, J. (2010). Stress and Burnout in Rural and Urban Secondary School teachers. The Journal of Educational Research, 92, 287-293. http://dx.doi.org/10.1080/00220679909597608

Bagdonas, A., \& Adaskevicienè, V. (2010). Manifestation of Comprehensive School Teachers' Psycho-Social Attitude. Social Sciences, 68(3), 60-70.

Chan, A.H.S. (2010). Proceedings of the International Multi-Conference of Engineers and Computer Scientist, 17-19 March., IMECS, Hong Kong.

Demirtas, Z. (2010). Teachers' job satisfaction levels. Procedia Social and Behavioural Sciences, 9, 1069-1073. http://dx.doi.org/10.1016/j.sbspro.2010.12.287

Harlow, P. (2010). Stress, coping, Job satisfaction and experience in teachers. A Thesis presented in partial fulfilment of the requirement for the degree of master in Arts in School Psychology. Dar es Salaam: University of Dar es salaam.

Kanene, M. K., \& Mushungelwa, M.D. (2016). Sources of Stress experienced by Secondary School Teachers in Choma District Southern Province, Zambia. (Unpublished). 
Klassen, R. M. (2010). Teacher Stress: The Mediating role of Collective Efficacy Beliefs, The Journal of Educational Research, 103(5), 342-350. http://dx.doi.org/10.1080/00220670903383069

Makasa, W. J. (2013). Perceived levels of occupational stress among basic school teachers: A Dissertation submitted to the University of Zambia in partial fulfilment of the requirements for the award of the degree of master of education in Educational Psychology, Lusaka, and University of Zambia.

Mlaki, E., \& Manase. J. (2012). Contribution of School location in manifestations of stress among public primary school head teachers in Tanzania, MUNICH, GRIN Verlag. Retrieved on $05 / 06 / 2015$.

Nabirye, R. C., Brown, K. C., Pryor, E. R., \& Maples, E. H. (2011). Occupational Stress, job satisfaction and job performance among hospital nurses in Kampala, Uganda. Journal of nursing management, 19(6), 760-768. http://dx.doi.org/10.1111/j.1365-2834.2011.01240.x

Purna, P. N., \& Gowthami, C. (2011). Source of Academic Stress a study on Management Students. Journal of Management Sciences; 1 (2), 31-42

Riaz, A., \& Ramzan. M. (2013). Recognition of stressors and manifestations of stress among university teachers. Interdisciplinary Journal of Contemporary Research, 4(9).

Richards, J. (2012). Teacher Stress and Coping Strategies: A National Snapshot. The Educational Forum, 76, 299-316. http://dx.doi.org/10.1080/00131725.2012.682837

Riggio, E., \& Ronald .E. (2013). Introduction to industrial and organisational psychology $\left(6^{\text {th }}\right.$ ed). New York: Pearson.

Schultz, P. D., \& Schult E.S. (2010). Psychology and work today $\left(10^{\text {th }}\right.$ Ed). New Jersey: Pearson Education Inc.

Romer, M. (2011).Teachers' work related stress: Assessing, comparing and evaluating. Brussells: European trade union committee for education.

Shahin, V., \& Nasser.F. (2011). The Relationship between Self-efficacy and Stress among Iranian EFL Teachers, Journal of Language Teaching and Research, 2(5), 1168-1174.

Soylu, S.E. (2013). Relationship Between the organisation climate and occupational stress experienced by English instructors in the preparatory school of five universities in Ankara- A Thesis submitted to the graduate school of social sciences of Middle East Technical University in partial fulfilment for Doctor

Sprenger, J. (2011). Stress and Coping behaviours among primary school teachers. A Thesis presented to the faculty the department of health education promotion at East Carolina University in Partial fulfilment of the requirements for the degree of Master of Arts.

Wilson, F.M. (2010). Organisational Behaviour and Work: A critical introduction ( $3^{\text {rd }}$ ed). New York: Oxford University Press. 